\title{
EL DISEÑO DE LA JURISDICCIÓN CONTENCIOSO-ADMINISTRATIVA EN MÉXICO, SUSTENTADA SOBRE UNA CONCEPCIÓN CIVILISTA
}

\author{
The contentious-administrative jurisdiction design in Mexico \\ based on a civil law conception
}

Pedro López Ríos

\begin{abstract}
“...aun cuando es propósito firme de los procesalistas estructurar un proceso administrativo autónomo y diferente al proceso civil, es innegable la actual influencia de éste no sólo como modelo sino como supletorio expreso del proceso administrativo," 2
\end{abstract}

Alfonso Nava Negrete

Sumario:

1. Introducción. II. Esencia de la jurisdicción. III. La concepción teórica de la jurisdicción civil. IV. Teoría del dualismo de los poderes públicos. La jurisdicción civil y la jurisdicción administrativa, su identidad esencial. Diferencias. V. El diseño del contencioso administrativo en México, basado en una concepción civilista. VI. Hacia un rediseño del proceso administrativo, con autonomía del proceso civil. VII. Conclusiones. VIII. Bibliografía.

Resumen: Este artículo plantea una reflexión sobre el proceso administrativo conforme a su naturaleza, apoyándose en tratadistas clásicos y en ordenamientos que constituyeron el modelo para el sistema mexicano; asimismo, ofrece algunos elementos para rediseñar el proceso administrativo, con autonomía del proceso civil.

Palabras clave: Proceso administrativo, justicia administrativa, contencioso administrativo.

Abstract: This article offers a theoretical framework to approach the nature of the administrative process. It draws upon classical theorists and the legal system that made up the model for the Mexican system. Likewise, this paper advances some clues to redesign the administrative process autonomously from the civil process.

Keywords: Administrative process, administrative justice.

\section{INTRODUCCIÓN}

El gran jurista romano Marco Tulio Cicerón, columna de la República Romana, nos enseña que la verdadera ley es la recta razón, concordante con la naturaleza de las cosas, y Juan Jacobo Rousseau sustenta que "si el legislador, equivocándose en su objeto, toma un camino diferente

\footnotetext{
${ }^{1}$ Profesor en el Departamento de Derecho de la División de Derecho, Política y Gobierno de la Universidad de Guanajuato. Exmagistrado del Tribunal de lo Contencioso Administrativo del Estado de Guanajuato

${ }^{2}$ Nava Negrete, Alfonso, Derecho procesal administrativo, Porrúa, México, 1959, p. 118.
} 
del indicado por la naturaleza de las cosas...se verán las leyes debilitarse insensiblemente, la constitución alterarse y el Estado no cesar de estar agitado hasta que, destruido o modificado, la invencible naturaleza haya recobrado su imperio". 3

Al respecto, es preciso señalar que la esencia del proceso administrativo no es declarativa del derecho, sino impugnativa o de control de la legalidad, debiendo el diseño metodológico coincidir con su naturaleza, lo que no ha acontecido en el sistema jurídico mexicano. Ya hace más de 50 años que el profesor Alfonso Nava Negrete planteaba como un desiderátum, o mejor, como una necesidad, la autonomía del proceso administrativo respecto del proceso civil, si bien, ambos dentro del contexto de una teoría general del proceso. Esta discordancia, entre la naturaleza jurídica y el método propio del proceso administrativo, constituye a mi juicio, uno de los problemas capitales de la teoría general del proceso, que trascienden de manera significativa al ámbito normativo: ordinario y constitucional, a la impartición de justicia, al ejercicio de la abogacía y a la vida académica misma.

\section{ESENCIA DE LA JURISDICCIÓN}

Partir de una clara concepción de lo que sea la jurisdicción nos abre las puertas para resolver el problema referido. De acuerdo con su semántica, jurisdicción proviene del vocablo latino jus dicere, que significa decir o declarar el derecho. En congruencia, la jurisdicción puede definirse como "la actividad del Estado encaminada a la actuación del derecho positivo mediante la aplicación de la norma general al caso concreto". ${ }^{4}$ Su etimología permite dar a esta voz un sentido amplio, al comprender tanto a la actividad del poder judicial como a la del poder ejecutivo. En el poder judicial, son los jueces quienes dicen el derecho, siguiendo un proceso de conocimiento; en el ejecutivo, son los órganos ejecutivos o administrativos quienes dicen el derecho, siguiendo asimismo un procedimiento histórico.

Los teóricos del proceso nos ofrecen definiciones coincidentes respecto a lo que sea la función jurisdiccional, y señalan en esencia, siguiendo a Calamandrei, que desde el punto de vista material o funcional, esto es, de acuerdo con su naturaleza, la jurisdicción consiste en "el poder de hacer observar en concreto las normas ya establecidas"; 5 ello, independientemente del criterio formal u orgánico, esto es, del órgano del que emana la declaración del derecho.

Este ejercicio de aplicación: si se hace a instancia de parte o de oficio, si previamente existe una controversia o no, si con esta aplicación se satisface un interés público o privado, siendo cuestiones relevantes no alteran su esencia, como se verá más adelante.

\section{LA CONCEPCIÓN TEÓRICA DE LA JURISDICCIÓN CIVIL}

La concepción teórica del proceso civil es, sin duda, fruto del talento y del esfuerzo por siglos de sus académicos, una concepción recogida por los legisladores que merece ser asumida como un modelo por los cultores de las demás disciplinas jurídicas, en su justa dimensión.

Los teóricos civilistas están muy orgullosos de su trabajo y con toda razón, pero también reconocen sus limitaciones. Qué mejor que traer a la memoria a uno de sus clásicos: Fran-

\footnotetext{
${ }^{3}$ Rousseau, Jean-Jacques, El contrato social, Grupo Editorial Éxodo, México, 2005, p. 47.

${ }^{4}$ De Pina, Rafael y De Pina Vara, Rafael, voz “Jurisdicción”, Diccionario de Derecho, Porrúa, México, 1995, p. 339.

${ }^{5}$ Citado por Armienta Calderón, Gonzalo M., Teoría general del proceso, Porrúa, México, 20o6, p. 48. 
cesco Carnelutti, quien nos dice en su obra: El sistema de derecho procesal civil, de manera por demás sincera, realista y visionaria: "En este libro, como en mi cátedra, se enseña sólo Derecho procesal civil. Hasta cierto punto, esta restricción es una necesidad impuesta por la limitación de las fuerzas humanas. Un sistema que abarque juntos todos los tipos de proceso, si bien es idealmente posible, temo que determinaría los inconvenientes de un edificio de dimensiones excesivas... Por otra parte, a la vez que me ajusto a esa necesidad, deseo manifestar con mayor firmeza todavía, el convencimiento de la unidad fundamental de todas las formas del proceso. Esta unidad se revela en la función común y, por correlación necesaria, en la comunidad esencial de la estructura, y no resulta destruida por diferencias secundarias. Un estudio completo de los distintos procesos no podría, desde luego, hacerse sin tener en cuenta esas diferencias; pero tanto o más nocivo resultaría perder de vista su fundamental unidad. Estoy seguro de no equivocarme al afirmar que la ciencia del Derecho procesal no alcanzará su cima hasta que no se haya construido sólidamente una parte general, en que los elementos comunes a cualquier forma de proceso encuentren su elaboración". ${ }^{6}$

Carnelutti define a la jurisdicción civil como "la potestad conferida por el Estado a determinados órganos para resolver mediante la sentencia las cuestiones litigiosas que les sean sometidas y hacer cumplir sus propias resoluciones". " Esta definición, clara y precisa para el ámbito del Derecho Civil, resulta ser un ejemplo de definición acotada a su propia disciplina, y ha ejercido una indudable influencia, casi avasalladora, como un modelo para los demás tipos de jurisdicción, en especial para el derecho administrativo, cuyos teóricos la han aceptado sin mayor reflexión en su propio campo.

Habrá que reconocer que "la ciencia de derecho administrativo es de relativa reciente aparición, por cuya razón es aún un disciplina en formación; su gestación se ubica en la Francia revolucionaria, durante la época de la Asamblea Constituyente, como producto de la sistematización de los principios racionales que fundan la acción administrativa, las atribuciones del poder público, los caracteres esenciales de las instituciones administrativas, así como los derechos humanos". ${ }^{8}$

IV. TEORÍA DEL DUALISMO DE LOS PODERES PÚBLICOS.LA JURISDICCIÓN CIVIL Y LA JURISDICCIÓN ADMINISTRATIVA, SU IDENTIDAD ESENCIAL. DIFERENCIAS.

En este tema es punto fundamental la teoría del dualismo de poderes públicos, y el apoyo en tres grandes teóricos: a) Carlos Luis de Secondat, Barón de la Brede y de Montesquieu, ese gran pensador de la ilustración, quien en su obra: Del espíritu de las leyes, publicada en 1748, expresa: "En cada Estado hay tres clases de poderes: el poder legislativo, el poder ejecutivo de las cosas relativas al derecho de gentes, y el poder ejecutivo de las cosas que dependen del derecho civil. En virtud del primero, el príncipe o jefe del Estado hace leyes transitoria o definitivas, o deroga las existentes. Por el segundo, hace la paz o la guerra, envía y recibe embajadas, establece la seguridad pública y precave las invasiones. Por el tercero, castiga los

\footnotetext{
${ }^{6}$ Carnelutti, Francesco, Sistema de derecho procesal civil, trad. de Niceto Alcalá Zamora y Castillo y Santiago Sentís Melendo, Cárdenas Editor, México, 1998, p. 306.

${ }^{7}$ Citado por Armienta, op. cit., nota 5, p. 49.

${ }^{8}$ Fernández Ruiz, Jorge y López Acosta, Santiago, Derecho administrativo del Estado de Guanajuato, PorrúaUNAM, México, 2008, p. XXVI.
} 
delitos y juzga las diferencias entre particulares. Se llama a este último poder judicial, y al otro poder ejecutivo del Estado". ${ }^{9}$

En el párrafo trascrito, Montesquieu menciona dos veces al poder ejecutivo, cuando se refiere al poder ejecutivo de las cosas relativas al derecho de gentes y al poder ejecutivo de las cosas que dependen del derecho civil, de donde se desprende que este autor plantea originariamente la tesis dualista de poderes: el poder legislativo, cuya función es la creación de las normas jurídicas generales, y los poderes ejecutivo y judicial, cuya función es la ejecución de las leyes; pero además plantea la diferenciación de los poderes ejecutivos basada en la naturaleza jurídica de las normas generales bajo su jurisdicción. Como una secuencia de su pensamiento, en otra parte de su obra nos dice, refiriéndose al poder judicial, que: "Podría ocurrir que la Ley, que es al mismo tiempo previsora y ciega, fuese, en casos dados, excesivamente rigurosa. Pero los jueces de nación, como es sabido, no son más ni menos que la boca que pronuncia las palabras de la ley...." ${ }^{10}$

En el contexto de esta teoría, planteada por Montesquieu, podemos asimilar al juez con el órgano administrativo, quien, asimismo, al aplicar la norma general al caso concreto, no es ni más ni menos que "la boca que pronuncia las palabras de la ley"; ello explica, por qué en el ámbito administrativo no hay jueces, ya que la función de declarar el derecho lo hace el órgano administrativo, y hay sólo "magistrados", como en el poder judicial, que revisan si la aplicación del derecho se hizo o no correctamente, esto es, si la norma individualizada es congruente con la norma general.

b) Jean-Jacques Rousseau, en su obra: El contrato social, publicada en 1760, señala siguiendo a Montesquieu, que "La soberanía es indivisible por la misma razón que es inalienable; porque la voluntad es general, o no lo es; la declaración de esta voluntad constituye un acto de soberanía y es ley, en el segundo, no es sino una voluntad particular o un acto de magistratura; un decreto a lo más. Pero nuestros políticos, no pudiendo dividir la soberanía en principio, la dividen en sus fines y su objeto: en fuerza y voluntad, en poder legislativo y en poder ejecutivo"; ${ }^{11}$ y continúa, refiriéndose al gobierno en general, que "En toda acción libre hay dos causas que concurren a producirla: la una moral, o sea la voluntad que determina el acto; la otra física, o sea la potencia que la ejecuta. Cuando camino hacia el objeto, necesito primeramente querer ir, y en segundo lugar, que mis pies puedan llevarme. Un paralítico que quiera correr, como un hombre ágil que no quiera, permanecerán ambos en igual situación. En el cuerpo político hay los mismos móviles: se distinguen en él la fuerza y la voluntad; ésta bajo el nombre de Poder Legislativo, la otra bajo el de Poder Ejecutivo..." El poder ejecutivo consiste así, en actos particulares que se desarrollan bajo la dirección de la voluntad general.

c) Hans Kelsen, en su obra: Esencia y valor de la democracia, editada en 1920, plantea el tópico de la dualidad cuando se refiere al proceso de democratización del "segundo grado en el proceso de volición estatal", esto es, a "aquellos actos individuales de voluntad del Estado que se incluyen bajo los enunciados de administración de justicia y de administración pública, integrantes de la función ejecutiva en sentido amplio"; ${ }^{12}$ y lo desarrolla como punto

\footnotetext{
${ }^{9}$ Montesquieu, Del espíritu de las leyes, trad. de Nicolás Estévanez, Porrúa, México, 1982, p. 104.

${ }^{10}$ Ibidem, p. 108.

${ }^{11}$ Rousseau, Jean-Jacques, op. cit., nota 3, p. 47.

${ }^{12}$ Kelsen, Hans, Esencia y valor de la democracia, trad. de Rafael Luengo Tapia y Luis Legaz y Lacambra, Colofón, México, 1992, p. 100.
} 
central de su obra: Teoría general del estado, publicada en $1925,{ }^{13}$ expresando en su Compendio de teoría general del estado, escrito por él mismo, al referirse a la creación del orden estatal y, en específico, a los grados de producción del derecho, que: "Según la concepción tradicional, el poder unitario del Estado se descompone en tres poderes coordinados entre sí: el legislativo, el ejecutivo y el judicial. En estos tres poderes deben encontrar expresión las tras funciones fundamentales del Estado: la Legislación, la Jurisdicción o Jurisprudencia (declaración del derecho) y la Administración. Ahora bien, puesto que toda función del Estado es función del Derecho, la teoría de las funciones del Estado habrá de concebir al Derecho en su funcionamiento, es decir, el movimiento propio y específico del Derecho; o lo que es igual, el Derecho desde el punto de vista de su dinámica. Por consiguiente, función del Estado es función creadora de Derecho; es el proceso graduado (o escalonado) y sucesivo del establecimiento de las normas... En todo caso, no se trata de funciones colocadas en el mismo plano, exentas de relación y esencialmente diferenciadas entre sí, sino de una serie de grados de la producción del derecho que determina una relación de subordinación". ${ }^{14}$

Posteriormente, en su Teoría general del derecho y del estado, editada en 1944 siendo profesor en la Universidad de Berkeley, California, reitera: que las funciones ejecutiva y judicial son esencialmente idénticas, y que el llamado "procedimiento administrativo" es una expresión soberana de jurisdicción, al igual que el proceso judicial.

En esencia, ésta es la reflexión que sobre el tema de la jurisdicción administrativa y de la jurisdicción civil nos hace este teórico de la ciencia política y del derecho: que las tres grandes funciones públicas, en realidad se refieren a dos grados de volición, el consistente en la creación de normas generales y, el segundo, en la génesis de normas individualizadas. Así, textualmente en su obra de 1944, expresa: "La usual tricotomía se basa en realidad en una dicotomía. La función legislativa suele oponerse a un mismo tiempo a las funciones ejecutiva y judicial, que, tienen entre sí una relación mucho mayor que guardan con la primera. La legislación (legis latio del derecho romano es la creación de leyes (leges). Si hablamos de ejecución tenemos que preguntarnos qué es lo que se ejecuta. La respuesta no puede ser otra sino que lo que se ejecuta son las normas generales, es decir, la Constitución y las leyes creadas por el poder legislativo. La función de ambos es realmente la misma. Las normas jurídicas generales son ejecutadas tanto por el poder ejecutivo como por el judicial. La diferencia estriba solamente en que, en un caso, la ejecución de las normas generales es confiada a los tribunales, y en el otro a los llamados órganos "ejecutivos" o administrativos. La tricotomía usual es pues, en el fondo, una dicotomía, es decir, la distinción fundamental entre legis latio y legis executio. La última es subdividida en las funciones judicial y ejecutiva en sentido estricto".$^{15}$

La jurisdicción administrativa: el procedimiento y el acto administrativo. De la tesis sobre la identidad esencial de la funciones ejecutiva y judicial, derivan otras, relativas al modo de ser de la jurisdicción administrativa. Al respecto, el fundador de la Escuela de Viena sostiene que "Aquellas leyes y reglamentos que, en atención a su contenido, reciben tradicional-

\footnotetext{
${ }^{13}$ Kelsen, Hans, Teoría general del estado, trad. de Luis Legaz y Lacambra, ed. Nacional, México, año de reimpresión 1972, pp. 311-322.

${ }^{14}$ Kelsen, Hans, Compendio de teoría general del estado, trad. de Luis Recasés Siches y Justino de Azcárate Colofón, México, 1992, pp. 189-19o.

${ }^{15}$ Kelsen, Hans, Teoría general del derecho y del estado, Trad. Eduardo García Máynez, UNAM, México, 1979, pp. 302-335.
} 
mente el nombre de "preceptos administrativos" -como las leyes relativas a la industria, a la sanidad, a la enseñanza, etc. - son aplicadas en concreto exactamente del mismo modo que las llamadas leyes judiciales: una autoridad constata el hecho establecido por la norma general como condición del acto coactivo, y aplica la consecuencia jurídica... En el acto administrativo como la sentencia judicial "realízase un acto de jurisdicción, de creación de normas individuales. La distinción entre uno y otro es una mera diferencia técnica”. ${ }^{16}$

En este punto, parece coincidir Chiovenda cuando expresa "La jurisdicción que actúa en las relaciones públicas, esto es, que median entre el particular y la Administración como "poder", cualesquiera que sean los órganos a los cuales se confía, puede llamarse con nombre complexivo jurisdicción "administrativa”, mientras que la jurisdicción "civil” en sentido estricto significa la jurisdicción que actúa en las relaciones entre particulares (comprendidas las relaciones en las cuales interviene la Administración), pero obrando como particular". ${ }^{17}$ Lo anterior, no obstante su reconocimiento de gran dificultad para su diferenciación, cuando ambos: proceso y procedimiento concluyen, como ya antes se dijo, en una sentencia o en un acto administrativo. Mas Chiovenda nos dice algo que aún nos reta en su comprensión: "Que deberá decirse de los actos de naturaleza jurisdiccional provenientes del poder administrativo? ¿Son de considerarse como actos administrativos? La cuestión es muy escabrosa porque es difícil la distinción funcional entre acto administrativo y acto jurisdiccional"; ${ }^{18}$ y es que, si una y otra función corresponden a poderes que aplican la norma general al caso concreto, creando normas individualizadas, ambos tienen -en esencia- poder jurisdiccional. Con esta visión funcional coincide el profesor Ovalle Favela, quien expresa: "Pero la expedición de estas jurídicas generales por los poderes judicial y ejecutivo no constituyen el contenido fundamental de las funciones jurisdiccional y ejecutiva. El resultado normal de estas funciones es la creación de normas jurídicas individualizadas, aplicables a personas determinadas y a situaciones jurídicas concretas. Tanto la sentencia como el acto administrativo contienen una norma jurídica que no es general, sino individualizada...ambas conciernen a situaciones jurídicas concretas, y no a situaciones jurídicas abstractas. Por eso se suele decir que, por medio de la función legislativa se crea o se modifica la ley; y a través de las funciones jurisdiccional y ejecutiva, normalmente se aplica aquella" ${ }^{19}$ y más delante en su propia obra: "La función ejecutiva, como su nombre lo indica, se dirige a la ejecución de las leyes, y en esto se asemeja a la función jurisdiccional". ${ }^{\circ}$

Sobre el procedimiento administrativo, Kelsen sostiene que "Si la Constitución prescribe que ninguna interferencia con la propiedad, libertad o vida del individuo puede tener lugar si no es mediante un "juicio previo", esto no implica necesariamente un monopolio de los tribunales relativamente a la función judicial. El procedimiento administrativo puede estructurarse de tal manera que corresponda al ideal del "juicio previo", ${ }^{21}$ en la fase histórica $y$, en ella, al igual que en el proceso judicial, la prueba es un elemento clave para la dicción del derecho, siendo aplicable el aforismo romano: da mihi factum, dabo tibi jus.

\footnotetext{
${ }^{16}$ Kelsen, op. cit., nota 15, p. 311.

${ }^{17}$ Chiovenda, José, Principios de derecho procesal civil, trad. de José Casais y Santaló, Cárdenas editor, México, 1980, t. 1, p. 409.

${ }^{18}$ Chiovenda, Giuseppe, Lezioni di diritto amministrativo, Giuffré Editore, Milán, 1991, p. 113.

${ }^{19}$ Ovalle Favela, José, Teoría general del proceso, Harla, México, 1994, pp. 111-112..

${ }^{20}$ Ibidem, p. 116.

${ }^{21}$ Kelsen, op. cit., nota 15, p. 330. 
En uno y otro caso, el proceso judicial o del procedimiento administrativo son idénticos desde el punto de vista material o de su naturaleza jurídica, ya que para su emisión se deben respetar las garantías de competencia, audiencia y legalidad; y su producto: el acto administrativo, al igual que la sentencia, debe estar fundado y motivado. Así, la Suprema Corte de Justicia de nuestro país ha sustentado la siguiente tesis jurisprudencial: "FUNDAMENTACIÓN Y MOTIVACIÓN. De acuerdo con el artículo 16 de la Constitución Federal, todo acto de autoridad debe estar adecuada y suficientemente fundado y motivado, entendiéndose por lo primero que ha de expresarse con precisión el precepto legal aplicable al caso y, por lo segundo, que también deben señalarse, con precisión, las circunstancias especiales, razones particulares o causas inmediatas que se hayan tenido en consideración para la emisión del acto; siendo necesario, además, que exista adecuación entre los motivos aducidos y las normas aplicables, es decir, que en el caso concreto se configuren las hipótesis normativas". Jurisprudencia. Materia(s): Común. Séptima Época. Instancia: Segunda Sala.

Pero además, la sentencia y el acto administrativo son idénticos en su estructura: resultandos, considerandos y puntos resolutivos, y gozan de presunción de legalidad, que sólo podría ser destruida mediante una acción impugnativa, por tal razón, ambos gozan de ejecutoriedad.

Diferencias entre las funciones administrativa y judicial. Al respecto, cabe señalar que la unidad fundamental entre proceso judicial y procedimiento administrativo se revela, como señala Carnelutti en la nota 6 del presente ensayo, en la función común de todas las formas del proceso a que antes se hizo referencia, y sus diferencias sustantivas, propias de cada tipo de jurisdicción, se dan en tres puntos, esencialmente: a) por el campo normativo de ejecución. En la función administrativa se aplica, como señala Montesquieu, el de las cosas relativas al derecho de gentes, y la judicial, a las cosas que dependen del derecho civil; b) por los sujetos. Conforme a Carnelutti y Kelsen, la ejecutiva se confía a los órganos administrativos, e intervienen dos personas: el administrado y el órgano administrativo, mientras que la judicial se confía a los tribunales e intervienen tres personas: el juzgador y dos partes, la que ejerce una pretensión y contra quien se pretende; y c) Por el objeto. La función administrativa tiende a la realización de un interés público, sin que exista una controversia, mientras la judicial, conforme a la definición de Carnelutti, a resolver cuestiones litigiosas que le sean sometidas, esto es, a la composición de un interés privado en conflicto. Al respecto, el profesor vienés expresa "El procedimiento judicial tiene usualmente la forma de una controversia entre partes. Una de ellas pretende que el derecho ha sido violado por la otra, o que ésta es responsable de una violación jurídica cometida por otro individuo, y la parte contraria niega que este sea el caso. La sentencia judicial es la resolución de una controversia. Desde el punto de vista de la norma general que tiene que ser ejecutada a través del ejercicio de la función judicial, el carácter polémico del procedimiento judicial es de importancia secundaria".22

V. EL DISEÑO DEL CONTENCIOSO ADMINISTRATIVO EN MÉXICO, BASADO EN UNA CONCEPCIÓN CIVILISTA

Sustentado que el procedimiento administrativo es materialmente jurisdiccional, tenemos que, como en el judicial, se dan las fases clásicas para la aplicación del derecho, como son: a) declarativa del derecho a que antes se hizo referencia, b) impugnativa, de revisión o de

\footnotetext{
${ }^{22}$ Kelsen, op. cit., nota 15, p. 324 .
} 
control jurídico, también denominada "contencioso-administrativa" a que ahora nos enfocaremos, y c) ejecutiva.

Respecto de la impugnativa, revisora o de control jurídico de la norma individualizada, el problema más general estriba, conforme al tratadista austriaco "en garantizar que una norma inferior se ajuste a la superior que determina su creación o su contenido... el derecho positivo conoce dos métodos para asegurar la concordancia entre una norma inferior y otra superior. El orden jurídico puede establecer un procedimiento por el cual es examinada la conformidad de la norma inferior con la superior, pudiendo la primera ser abolida si se descubre que no concuerda con la segunda. El orden jurídico puede también hacer personalmente responsable al órgano que crea una norma ilegal”. Continúa este tratadista señalando que la teoría de la separación de poderes "parece exigir que ninguno de los tres poderes sea controlado por cualquiera de los otros dos. Sin embargo, este principio es el que se invoca para justificar el más estricto control de la administración por los tribunales...", "Si la Constitución de un régimen democrático establece... el control de las funciones legislativa y administrativa por los tribunales, ello sólo puede explicarse por razones históricas". ${ }^{23}$ En la actualidad, dicho control jurídico se realiza en México por los tribunales ubicados en el poder ejecutivo, conforme a la tradición continental europea, en el judicial, según la tradición anglosajona, o bien autónomos de los poderes públicos mencionados; pero independientemente de su adscripción formal, lo importante es que garanticen la concordancia de la norma jurídica individualizada con la ley, como expresión de la voluntad general.

El contencioso administrativo, su origen. En nuestro país, la formas del proceso impugnativo administrativo tienen su fuente de inspiración en el sistema francés. Así sucedió con la trascendental creación de la jurisdicción contenciosa administrativa en materia fiscal, realizada mediante la Ley de Justicia Fiscal de 27 de agosto de 1936. Esta Ley, que evolucionó hasta ser comprensiva a la fecha de toda la materia administrativa federal, conforme a la vigente Ley Federal de Procedimiento Contencioso Administrativo publicada en el Diario Oficial de la Federación el $1^{\circ}$ de diciembre de 2005, ha servido de modelo al sistema contencioso-administrativo local. Don Alfonso Cortina Gutiérrez, uno de los integrantes de la Comisión para el diseño de dicha Ley, y antiguo profesor de teoría general de la tributación en la UNAM, expresa: "Nuestro juicio tributario es muy francés. No es italiano, ni menos anglosajón... El meollo del contencioso administrativo está en el de anulación y en el de plena jurisdicción. El recurso de anulación está dirigido siempre en contra de una "decisión ejecutoria", es decir, de un acto administrativo que emana unilateralmente de un órgano del Estado, dentro de su actuación soberana, de su poder de imperio; acto que por el interés general que corresponde al campo del derecho público en el que se desarrollan las funciones estatales, es ejecutable "per se", sin previas formalidades de orden judicial"; y continúa señalando "Ya puedo afirmar, una vez más, que el juicio ante el Tribunal Fiscal es un juicio de anulación en algunos casos, pero también de plena jurisdicción en otros casos. Que el Código Fiscal de la Federación haya previsto originalmente un recurso por exceso de poder en el sentido francés, es evidente, pues basta leer su artículo 202 para darse cuenta no sólo de que expresamente la ley habla de causas de anulación, sino también de que las cuatro causas que ese precepto señala son idénticas a las "ouvertures" del exceso de poder en Francia”. ${ }^{24}$

\footnotetext{
${ }^{23}$ Ibidem, pp. 316 y $332-335$.

${ }^{24}$ Cortina Gutiérrez, Alfonso, "El control jurisdiccional administrativo de la legalidad y de la facultad discrecional”, Revista del Tribunal Fiscal de la Federación, número extraordinario, 1965, México, pp. 70-71 y 79. 
Pero, nos preguntamos ¿de dónde surge la denominación de: juicio (y no recurso, como en el sistema francés), de partes, de demanda y contestación, de que serán admisibles toda clase de pruebas (como si se tratara de un proceso de conocimiento o histórico), de que mediante el procedimiento contencioso se está resolviendo una controversia, de que a falta de prevención expresa se aplicará las del Código de Procedimientos Civiles, elementos todos ellos que se ubican en la Ley de Justicia Fiscal de 1936?. Sin duda, todos estos elementos no son propios de un proceso impugnativo, sino de uno de conocimiento o de declaración del derecho, y más propiamente de uno de índole civil? ¿Qué conforme al sistema francés de origen, no se dijo antes que se trata de un recurso por exceso de poder?, ésta y otras interrogantes no tendrán respuesta por ahora en este espacio, pero sí al menos se establece que hay una clara confusión en la naturaleza jurídica de este proceso. Confusión que no sólo aconteció con el legislador ordinario de 1936, sino que aún se contiene actualmente, conforme a la Ley Federal del Procedimiento Contencioso Administrativo (Diario Oficial de la Federación el $^{\circ}{ }^{\circ}$ de diciembre de 2005, cuya última reforma se publicó el 28 de enero de 2011). Más grave aún, cuando esta confusión se da no sólo en la Ley ordinaria, sino también en el intérprete de la norma suprema de nuestro país, la Segunda Sala de la Suprema Corte, que estableció la siguiente tesis de jurisprudencia bajo el rubro: "CONTENCIOSO ADMINISTRATIVO. LAS PRUEBAS DEBEN ADMITIRSE EN EL JUICIO Y VALORARSE EN LA SENTENCIA, AUN CUANDO NO SE HUBIERAN OFRECIDO EN EL PROCEDIMIENTO”. Contradicción de tesis 80/2001-SS. Entre las sustentadas por los Tribunales Colegiados Segundo del Décimo Cuarto Circuito, Segundo en Materia de Trabajo del Cuarto Circuito y Primero en Materia Administrativa del Sexto Circuito. 14 de noviembre de 2001. Cinco votos. Ponente: Sergio Salvador Aguirre Anguiano. Secretaria: Rosalía Argumosa López. Tesis de jurisprudencia 69/2001. Aprobada por la Segunda Sala de este Alto Tribunal, en sesión privada del veintitrés de noviembre de dos mil uno. Dicha tesis se refiere a la presunción de legalidad de que goza la resolución impugnada, al tenerse por consentidos hechos u omisiones consignados en el oficio de observaciones que no fueron desvirtuados de manera documental; no obstante, la tesis sostiene que admite prueba en contrario en caso de impugnarse la resolución, aun cuando no hayan sido planteados en la instancia administrativa, desvirtuándose así el sentido de un procedimiento administrativo, en que la autoridad concedió al particular el derecho de audiencia.

Pero además, el Constituyente federal establece, en diversas partes del texto constitucional (art. 73 fracción XXIX-H, 115 fracción II, 116 fracción V), refiriéndose a los medios impugnativos en materia administrativa, específicamente al contencioso administrativo: federal, municipal y estatal, respectivamente, que su objeto es el de dirimir controversias, elevando así a rango constitucional una confusión que se creía sólo en ley ordinaria, y aún más grave, el establecer en el primer artículo referido, que el contencioso administrativo federal tendrá a su cargo asimismo "imponer sanciones a los servidores públicos por responsabilidad administrativa”, lo que implica no sólo la confusión en referencia sino una absoluta distorsión de las fases de la función administrativa misma. Ejemplo de una clara equivocación constitucional, en la naturaleza de las cosas, al dotar al órgano revisor de una facultad declarativa del derecho, lo que trajo por consecuencia un rechazo funcional en el órgano mismo. 
Para que el Estado de Derecho logre su verdadera realización, como de manera precisa y contundente afirma el profesor Soto Guerrero, "es necesario que establezca, entre otros principios básicos de orden jurídico, una serie de medios de impugnación, a través de los cuales se pueden revocar o anular los actos de los poderes públicos lesivos de los derechos de los gobernados. Cuando falten garantías, cuando haya amplias zonas de la actividad pública a las que injustificadamente no llegan dichos medios de impugnación, puede afirmarse, sin temor a caer en el error, que el Estado de Derecho no existe". ${ }^{25}$

Conforme a la teoría de los medios de impugnación que dicho autor propone, específicamente en su parte especial: a) el acto impugnable lo es el acto administrativo, equivalente a la sentencia judicial, como antes se precisó, ya sea en única o en primera instancia; b) el acto impugnativo lo sería, no la demanda como se tiene diseñado, sino el recurso (por exceso de poder, como en Francia, o el recurso contencioso-administrativo español) contra dicho acto, y su pretensión: la declaración de no conformidad a derecho; en su caso, el reconocimiento de una situación jurídica individualizada y la adopción de las medidas adecuadas para su pleno restablecimiento, incluida la indemnización de los daños y perjuicios cuando proceda; c) el procedimiento será de índole impugnativo, y en él se deberá apreciar el acto tal cual fue emitido por la autoridad. En dicho procedimiento el elemento esencial se constituye por los agravios expuestos por el recurrente, sin que sea admisible prueba de hechos, salvo que ésta fuese superveniente. d) finalmente, la resolución habrá de ser congruente con la pretensión ejercida, y si, en su caso, fuere estimada procedente la pretensión de resarcimiento de daños y perjuicios, su concreción definitiva quedará diferida al período de ejecución de la resolución. En adición, ha de señalarse que la supletoriedad del proceso civil respecto del administrativo ha sido abandonada en varias legislaciones de las entidades federativas, comenzando con la del Estado de México, pionera en este aspecto en nuestro país, diseñando ya, en este punto, un proceso impugnativo autónomo del proceso civil.

Para un diseño de la forma impugnativa ya se tiene una metodología de revisión muy bien perfilada por el proceso civil, y ésta, no el proceso de conocimiento de demanda y contestación, podría servir para el proceso impugnativo en materia administrativa, porque es su equivalente en cuanto a su naturaleza jurídica. Así, puede servir como modelo el recurso de apelación civil, en que el magistrado revisa la sentencia a la luz de los agravios expuestos por el recurrente, sin que sea admisible siquiera un informe de la autoridad cuyo sentencia es recurrida. Otra metodología, que tiene un reconocimiento en nuestro sistema jurídico, y por el cual me pronunciaría, es el procedimiento adoptado para el juicio de amparo, en que a la autoridad emisora se le pide un informe, pero sin que su desahogo sea requisito indispensable para continuar el procedimiento de revisión. Si bien este proceso es para revisar el acto frente al texto constitucional, este método es perfectamente aplicable para su confrontación frente a la ley ordinaria.

Sin duda, que una impugnación basada sobre estos fundamentos, tendría viabilidad teórica, normativa y jurisprudencial, permitiendo una congruencia sistemática con otros procesos, como lo planteara ese gran teórico del proceso, Francesco Carnelutti, en la idea de

\footnotetext{
${ }^{25}$ Soto Guerrero, Salvador, "Los medios de impugnación (Reflexiones sobre una teoría general de la impugnación)", Investigaciones Jurídicas, Facultad de Derecho de la Universidad de Guanajuato, Boletín 35, Julioseptiembre de 1989, p. 172.
} 
construir una teoría general de la impugnación sencilla, comprensible, y ágil en torno a la consecución de la justicia.

\section{CONCLUSIONES}

Al menos tres conclusiones podemos desprender del presente ensayo:

a) Las funciones del Estado no son tres, sino dos: creación y aplicación (ejecución) de la ley. La distinción entre creación y aplicación del derecho sirve de base al dualismo propuesto por Montesquieu y Rousseau y desarrollado por Hans Kelsen. Las funciones ejecutiva y judicial son esencialmente idénticas, en cuanto transforman las normas generales en normas individualizadas.

b) La concepción del proceso administrativo como un proceso de conocimiento es contrario a su naturaleza jurídica, que es impugnativa.

c) El rediseño del proceso administrativo en México, conforme a la teoría general de la impugnación, encuentra su cauce similar, como un recurso de apelación en materia civil, o bien, como el juicio de amparo.

\section{BIBLIOGRAFÍA}

CARNELUTTI, Francesco, Sistema de derecho procesal civil, trad. de Niceto Alcalá Zamora y Castillo y Santiago Sentís Melendo, Cárdenas Editor, México, 1998.

CORTINA GUTIÉRREZ, Alfonso, "El control jurisdiccional administrativo de la legalidad y de la facultad discrecional", Revista del Tribunal Fiscal de la Federación, número extraordinario, 1965, México, pp. 70-71 y 79.

CHIOVENDA, José, Principios de derecho procesal civil, trad. de José Casais y Santaló, Cárdenas editor, México, 1980. t. 1.

CHIOVENDA, Giuseppe, Lezioni di diritto amministrativo, Giuffré Editore, Milán, 1991.

De PINA, Rafael y De PINA VARA, Rafael, voz "Jurisdicción”, Diccionario de Derecho, Porrúa, México, 1995.

FERNÁNDEZ Ruiz, Jorge y López Acosta, Santiago, Derecho administrativo del Estado de Guanajuato, Ed. Porrúa-UNAM, México, 2008, p. XXVI.

KELSEN, Hans, Esencia y valor de la democracia, trad. de Rafael Luengo Tapia y Luis Legaz y Lacambra, Colofón, México, 1992.

, Teoría general del estado, trad. de Luis Legaz y Lacambra, Ed. Nacional, México, año de reimpresión 1972.

, Compendio de Teoría general del Estado, trad. de Luis Recaséns Siches y Justino de Azcárate, Colofón, México, 1992.

, Teoría general del derecho y del estado, Trad. Eduardo García Máynez, UNAM, México, 1979.

MONTESQUIEU, Del espíritu de las leyes, trad. de Nicolás Estévanez, Porrúa, México, 1982.

NAVA NEGRETE, Alfonso, Derecho procesal administrativo, Ed. Porrúa, México, 1959. 
OVALLE FAVELA, José, Teoría general del proceso, Harla, México, 1994.

ROUSSEAU, Jean-Jacques, El contrato social, Grupo Editorial Éxodo, México, 2005.

SOTO GUERRERO, Salvador, "Los medios de impugnación (Reflexiones sobre una teoría general de la impugnación)", Investigaciones Jurídicas, Facultad de Derecho de la Universidad de Guanajuato, Boletín 35, julio-septiembre de 1989. 